\title{
PENENTUAN HARGA PREMI BERDASARKAN FUNGSI PERMINTAAN DAN TITIK KESETIMBANGANNYA DALAM PORTOFOLIO HETEROGEN
} (PREMIUM PRICING BASED ON DEMAND FUNCTION AND
EQUILIBRIUM POINT IN HETEROGENOUS PORTOFOLIO)

\author{
Usep Sholahudin ${ }^{1}$ \\ ${ }^{1}$ Universitas Serang Raya, sholahudin.usep@yahoo.com
}

\begin{abstract}
Abstrak
Penelitian ini mempelajari hubungan tarik menarik antara banyaknya tertanggung dan harga preminya ditiap kelas risiko pada portofolio heterogen. Pertama, penanggung menetapkan harga premi berdasarkan sejumlah tertanggung yang ditetapkan untuk masing-masing kelas risiko. Selanjutnya, pasar bereaksi yang mengakibatkan perubahan jumlah pemegang polis pada setiap kelas risiko. Sebagai konsekuensinya, penanggung menyesuaikan harga premi sebagai permintaan pasar, dan proses ini berulang sampai terpenuhi suatu keadaan tertentu. Proses tersebut telah dibuktikan memiliki titik kesetimbangan. Karakteristik dari titik kesetimbangan dibuktikan melalui teorema titik tetap. Selanjutnya, untuk mengilustrasikan teori, perhitungan harga premi berdasarkan fungsi permintaan dalam titik kesetimbangannya dilakukan untuk lima kelas risiko dengan menggunakan perangkat lunak Mathematica.
\end{abstract}

Kata kunci: portofolio, heterogen, premi, permintaan, kesetimbangan.

\begin{abstract}
This paper aims to study the interaction between the number of insured in each class of a heterogenous portfolio and its premium. First, the insurers determines the premiums based on some initial number of insured in each class. Then, market reacts by updating the number of the policyholders. As a consequence, the insurer updates the premium. This process repeats until a certain condition is satisfied. This process has been proved to have an equilibrium point. The characteristics of the equilibrium point are determined by the fixed-point theorem. Finally, to illustrate the theory, the calculation of premium based on a demand function in equilibrium point for five risk classes is applied using Mathematica software.
\end{abstract}

Keywords: heterogenous portfolio, premium pricing, demand function, equilibrium point, the fixed-point theorem

\section{PENDAHULUAN}

Penentuan harga premi merupakan salah satu fungsi yang rawan dalam perusahaan asuransi. Harga premi yang ditentukan dikatakan wajar (fair premium) 
yaitu harus cukup tinggi untuk meliput beban pembayaran klaim tetapi cukup rendah sehingga kompetitif dengan besarnya premi perusahaan asuransi lain.

Perhitungan harga premi dibuat dalam suatu portofolio. Portofolio heterogen terdiri dari beberapa kelas risiko dan perhitungan harga premi ditentukan berdasarkan parameter rataan dan ragam masing-masing kelas.

Beberapa penelitian mengenai penentuan harga premi telah dilakukan sebelumnya, antara lain oleh Bowers dkk. (1997) yang menyatakan bahwa pendekatan standar untuk penentuan besarnya premi berdasarkan konsep faktor loading, menurut konsep ini besarnya premi $(\pi)$ untuk suatu risiko (the premium for a risk) adalah $\pi=\mu(1+\theta)$, dimana $\mu$ merupakan rataan dari risiko (the risk's mean), dan $\theta$ adalah faktor loading. Faktor loading diperoleh dengan syarat peluang kebangkrutan (insolvency probability) di bawah suatu nilai yang ditetapkan yaitu $\alpha$.

Zaks dkk. (2006) dan Frostig dkk. (2006) menyatakan, penentuan harga premi pada portofolio heterogen merupakan solusi dari suatu masalah pengoptimuman. Pada proses pengoptimuman harus memperhatikan dua prinsip utama, prinsip pertama menyatakan peluang dari seluruh klaim melampaui premi total yang diterima (peluang kebangkrutan) ditetapkan sebesar $\alpha$, prinsip yang kedua yaitu besarnya premi akan diperhitungkan naik pada saat perkiraan jumlah klaim naik.

Menurut Kliger dan Levikson (1998), fungsi yang menyatakan banyaknya tertanggung $(n)$ menurut harga preminya $(\pi)$, disebut fungsi permintaan (demand function) atau $n=f(\pi)$, dan diasumsikan fungsi tersebut adalah fungsi turun.

Pada penelitian ini akan dibahas mengenai hubungan tarik menarik (interplay) antara banyaknya peserta asuransi (tertanggung) untuk tiap kelas risiko dalam suatu portofolio heterogen dengan harga premi masing-masing. Untuk para pemegang polis, perusahaan-perusahaan asuransi menetapkan harga premi, selanjutnya pasar bereaksi dengan pembaruan (updating) jumlah pemegang polis. Hal ini menyebabkan pembaruan harga premi, dan seterusnya. Akan diperlihatkan dalam proses tersebut terdapat titik kesetimbangan (equilibrium point).

\section{KAJIAN TEORI}

\section{Model Risiko Individu Jangka Pendek}

Dalam perhitungan asuransi, misalkan peubah acak kerugian dari tiap risiko dilambangkan dengan $S$. Model risiko individu jangka pendek didefinisikan:

$$
S=X_{1}+X_{2}+\cdots+X_{n}
$$

dimana $X_{i}$ menyatakan besarnya kerugian tertanggung dari unit ke- $i$, dan $n$ adalah banyaknya unit risiko tertanggung, dan dikatakan jangka pendek karena tidak mempertimbangkan perubahan nilai uang.

(Bowers dkk. 1997)

\section{Model Peubah Acak Klaim Individu}

Pada suatu produk asuransi jiwa dalam satu jangka pembayaran, misalkan peserta membayar sebesar $b$, peluang klaim dari peserta sebesar $q$. Peubah acak klaim $(X)$ dengan fungsi massa peluang seperti berikut 
dan fungsi sebaran peluangnya

$$
f_{X}(x)=P(X=x)=\left\{\begin{array}{cl}
1-q & , x=0 \\
q & , x=b \\
0 & , \text { selainnya }
\end{array}\right.
$$

$$
F_{X}(x)=P(X \leq x)=\left\{\begin{array}{cl}
0 & , x<0 \\
1-q & , 0 \leq x<b \\
1 & , x \geq b .
\end{array}\right.
$$

Dari (1) didapat:

$$
\begin{gathered}
E(X)=b q \\
E\left(X^{2}\right)=b^{2} q \\
\operatorname{Var}(X)=b^{2} q(1-q) .
\end{gathered}
$$

Peubah acak $X$ juga dapat ditulis dalam

$$
X=I B
$$

dimana $X$ adalah peubah acak klaim dalam satu periode tertentu, $B$ menyatakan peubah acak klaim total dalam satu periode tersebut, dan $I$ adalah peubah acak indikator dimana $I=1$ jika terjadi klaim dan $I=0$ jika tidak terjadi klaim.

$E(X)$ dan $\operatorname{Var}(X)$ dapat diperoleh dengan menggunakan pendekatan

$$
\begin{gathered}
E(X)=E(E(X \mid I)), \\
\operatorname{Var}(X)=\operatorname{Var}(E(X \mid I))+E(\operatorname{Var}(X \mid I)),
\end{gathered}
$$

Selanjutnya

$$
\begin{gathered}
\mu=E[B \mid I=1], \\
\sigma^{2}=\operatorname{Var}(B \mid I=1),
\end{gathered}
$$

dan didapat

$$
\begin{gathered}
E[X]=\mu q, \\
\operatorname{Var}(X)=\mu^{2} q(1-q)+\sigma^{2} q .
\end{gathered}
$$

(Bowers dkk. 1997)

\section{METODE}

Metode penelitian yang digunakan dalam penelitian ini adalah studi pustaka, dengan langkah-langkah sebagai berikut:

1. Menentukan harga premi untuk tiap kelas risiko pada portofolio heterogen dengan menggunakan model dua pendekatan masalah pengoptimuman.

2. Mendefinisikan fungsi harga dan fungsi permintaan.

3. Menentukan eksistensi dan karakterisasi dari titik kesetimbangan antara fungsi harga dan fungsi permintaan.

4. Melakukan simulasi perhitungan harga premi pada titik kesetimbangan. 


\section{HASIL DAN PEMBAHASAN}

\section{Portofolio Heterogen}

Portofolio yang terdiri dari sejumlah $k$ kelas risiko dinamakan portofolio heterogen. Asumsi-asumsi berikut berlaku untuk portofolio ini yaitu:

(a) Risiko- risiko di dalam portofolio bersifat bebas stokastik.

(b) Pada kelas ke- $j$ yang terdiri atas sejumlah $n_{j}$ risiko bebas stokastik identik yaitu $X_{j, 1}, \cdots, X_{j, n_{j}}$ menyebar sebagai $X_{j}$, dengan rataan $\mu_{j}$ dan ragam $\sigma_{j}^{2}$, $j=1, \cdots, k$ dan $n=\sum_{j=1}^{k} n_{j}$.

(c) Banyaknya $n_{j}, j=1, \cdots, k$ cukup besar sehingga dapat diberlakukan Teorema Limit Pusat (TLP).

Misalkan $S_{j}=\sum_{i=1}^{n_{j}} X_{j, i}$ dan $S=\sum_{j=1}^{k} S_{j}$ adalah risiko total portofolio, menggunakan TLP dimana $S^{*} \sim N(0,1)$ dengan nilai rataan $\mu$ dan ragam $\sigma^{2}$ dimana,

$$
\mu=E[S]=\sum_{j=1}^{k} n_{j} \mu_{j} \quad \text { dan } \quad \sigma^{2}=\operatorname{var}[S]=\sum_{j=1}^{k} n_{j} \sigma_{j}^{2} .
$$

\section{Penentuan Harga Premi Menggunakan Model Dua Pendekatan Masalah Pengoptimuman}

Penentuan harga premi dengan alokasi optimum menggunakan dua pendekatan, yaitu pendekatan pertama kondisinya:

1. Menggunakan peluang kebangkrutan sebagai kendala.

2. Premi wajar yang akan ditetapkan, dihitung dengan meminimisasi kuadrat selisih antara risiko total dikurangi premi total yang terboboti.

Sedangkan pendekatan kedua adalah masalah dual dari pendekatan pertama.

\section{a. Pendekatan Pertama}

Menentukan vektor premi $\boldsymbol{\pi}=\left(\pi_{1}, \ldots, \pi_{n}\right)$ dengan cara meminimumkan penjumlahan nilai harapan dari kuadrat selisih antara risiko total dengan premi total yang diberikan bobot dengan kendala peluang premi total lebih kecil atau sama dengan risiko total (peluang kebangkrutan) di bawah nilai $\alpha$, yaitu:

$$
\min _{\pi}\left\{\sum_{j=1}^{k} \frac{1}{r_{j}} E\left(S_{j}-n_{j} \pi_{j}\right)^{2}\right\}
$$

dengan kendala,

$$
P\left(\sum_{j=1}^{k} n_{j} \pi_{j} \leq \sum_{j=1}^{k} S_{j}\right) \leq \alpha
$$

solusi untuk pendekatan pertama dengan fungsi tujuan (2) dan fungsi 
kendala (3) adalah:

$$
\pi_{j}=\mu_{j}+\frac{q_{1-\alpha} r_{j}}{r n_{j}} \sigma
$$

dimana $r_{j}=\frac{n_{j} \sigma_{j}^{2}}{\sigma^{2}}$ dan $r=\sum_{j=1}^{k} r_{j}$ sedangkan $q_{1-\alpha}$ adalah persentil $1-\alpha$ dari sebaran normal baku.

\section{b. Pendekatan kedua}

Penentuan vektor premi $\boldsymbol{\pi}=\left(\pi_{1}, \ldots, \pi_{n}\right)$, dengan cara meminimumkan peluang kebangkrutan dan sebagai kendala adalah nilai harapan dari $\sum_{j=1}^{k}\left(S_{j}-\right.$ $\left.n_{j} \pi_{j}\right)^{2}$ yang diberikan bobot di bawah suatu nilai yang telah ditentukan $(B)$, yaitu:

$$
\min _{\pi}\left\{P\left(\sum_{j=1}^{k} n_{j} \pi_{j}<\sum_{j=1}^{n} S_{j}\right)\right\}
$$

dengan kendala:

$$
\sum_{j=1}^{k}\left[\frac{1}{r_{j}} E\left(n_{j} \mu_{j}-n_{j} \pi_{j}\right)^{2}\right] \leq B
$$

Solusi untuk pendekatan kedua dengan fungsi tujuan (5) dan fungsi kendala (6) adalah:

$$
\pi_{j}=\mu_{j}+\frac{r_{j}}{n_{j}} \sqrt{\frac{A}{r}}, \quad \forall_{j}=1, \cdots, k
$$

dimana $A=\sum_{j=1}^{k} \frac{n_{j} \sigma_{j}^{2}}{r_{j}} \operatorname{dan} B=\sum_{j=1}^{k} \frac{n_{j} \sigma_{j}^{2}}{r_{j}}+\sum_{j=1}^{k} \frac{n_{j}}{r_{j}}\left(\pi_{j}-\mu_{j}\right)^{2}$.

\section{Fungsi Harga}

Solusi untuk dua pendekatan tersebut yaitu persamaan (4) dan (7), dapat dituliskan dalam formula lain. Misalkan diberikan vektor $\boldsymbol{n}=\left(n_{1}, \ldots, n_{k}\right)$ yang menyatakan banyaknya peserta asuransi dalam tiap kelas risiko $j=1, \cdots, k$, maka untuk kelas ke- $j$ besarnya premi $\pi_{j}$ yaitu $P_{j}(\boldsymbol{n})$ adalah:

$$
\pi_{j}=P_{j}(\boldsymbol{n})=\mu_{j}+\frac{r_{j}}{n_{j}} a
$$

dimana nilai $a$ untuk pendekatan pertama adalah $\frac{q_{1-\alpha} \sigma}{r}$, dan untuk pendekatan kedua adalah $\sqrt{\frac{A}{r}}$. Sehingga $\boldsymbol{P}(\boldsymbol{n})=\left(p_{1}(n), \ldots, p_{k}(n)\right)$ disebut fungsi harga $($ the 
pricing function).

\section{Eksistensi dan Karakteristik dari Titik Kesetimbangan}

\section{a. Eksistensi Titik Kesetimbangan}

Pada portofolio heterogen yang terdiri dari $j=1, \cdots, k$ kelas risiko, misalkan ditetapkan besarnya premi untuk masing-masing kelas sebagai suatu vektor premi $\boldsymbol{\pi}=\left(\pi_{1}, \ldots, \pi_{k}\right)$, akan berpotensi untuk menghasilkan vektor lainnya yaitu $\boldsymbol{n}=\boldsymbol{D}(\boldsymbol{\pi})=\left(D_{1}\left(\pi_{1}\right), \ldots, D_{k}\left(\pi_{k}\right)\right)$, dimana $D_{j}(\pi)$ adalah banyaknya potensi peserta asuransi pada kelas ke- $j$ dengan vektor premi $\boldsymbol{\pi}$. Dikatakan bahwa $\boldsymbol{D}(\boldsymbol{\pi})$ adalah fungsi permintaan, dan diasumsikan bila $D_{j}(\pi)$ turun ketika $\pi_{j}$ naik.

Hal tersebut dijelaskan dalam pasar asuransi, yaitu ketika sejumlah perusahaan asuransi menentukan harga premi bagi para pemegang polis, pasar bereaksi dengan pembaruan jumlah pemegang polis. Hal ini menyebabkan pembaruan harga premi, dan seterusnya.

Andaikan harga premi pada kelas ke- $j$ telah ditentukan, dan dimisalkan jumlah peserta pada kelas tersebut adalah $\boldsymbol{n}^{0}$, dimana $\boldsymbol{n}^{\mathbf{0}}=\left(n_{1}^{0}, \cdots, n_{k}^{0}\right)$. Harga premi ditentukan dengan menggunakan rumus fungsi harga (8), sehingga didapatkan vektor preminya untuk tiap kelas risiko yaitu

$$
\boldsymbol{\pi}^{\mathbf{1}}=\left(P_{1}\left(n^{0}\right), \cdots, P_{k}\left(n^{0}\right)\right)
$$

Pembaruan vektor premi ini, menyebabkan perubahan jumlah pemegang polis pada tiap kelas karena adanya fungsi permintaan, yaitu $\boldsymbol{n}^{\mathbf{1}}=\boldsymbol{D}\left(\boldsymbol{\pi}^{\mathbf{1}}\right)$, dan selanjutnya sampai pada langkah ke-j besarnya premi ditetapkan $\boldsymbol{\pi}^{\boldsymbol{j}}=$ $\left(P_{1}\left(n^{j-1}\right), \cdots, P_{k}\left(n^{j-1}\right)\right)$ lalu banyaknya tertanggung berubah menjadi $\boldsymbol{n}^{j}=$ $\boldsymbol{D}\left(\boldsymbol{\pi}^{j}\right)$, kemudian menjadi $\boldsymbol{\pi}^{\boldsymbol{j}+\boldsymbol{1}}=\left(P_{1}\left(n^{j}\right), \cdots, P_{k}\left(n^{j}\right)\right)$ dan seterusnya.

Vektor $\boldsymbol{\pi}^{*}$ dikatakan pada titik kesetimbangan pada saat $\boldsymbol{\pi}^{*}=P\left(\boldsymbol{D}\left(\boldsymbol{\pi}^{*}\right)\right)$, dimana $\boldsymbol{n}^{*}=\boldsymbol{D}\left(\boldsymbol{\pi}^{*}\right)$ yaitu banyaknya tertanggung pada tiap kelas sebagai fungsi dari $\boldsymbol{\pi}^{*}$. Penentuan eksistensi titik kesetimbangan menggunakan teorema:

\section{Teorema 1 Teorema Titik Tetap (Teorema Brouwer)}

Misalkan $C \subset R^{n}$ adalah gugus tak kosong, kompak, dan konveks. Fungsi $f: C \rightarrow C$ kontinu, maka terdapat titik tetap (fixed point) yaitu $x_{o}, x_{o}=f\left(x_{o}\right)$.

Dalam perhitungan penentuan besarnya premi $\left(\pi_{j}\right)$ dan jumlah tertanggung $\left(n_{j}\right)$, diasumsikan batasan intervalnya adalah:

(a) $\pi_{j} \in\left[\mu_{j}, M_{j}\right], j=1, \cdots, k$, dimana $0<N_{j}^{\min } \leq D_{j}(\pi) \leq N_{j}^{\max }$

(b) $n_{j} \in\left[N_{j}^{\min }, N_{j}^{\max }\right], j=1, \cdots, k$, dimana $\mu_{j} \leq \tilde{P}_{j}(n) \leq M_{j}$.

Dengan menggunakan Teorema 1 dan asumsi batasan interval, maka fungsi harga pada persamaan (8) menjadi

$$
\widetilde{\boldsymbol{P}}(\boldsymbol{n})=\left(P_{1}(n) \wedge M_{1}, \cdots, P_{k}(n) \wedge M_{k}\right)
$$

\section{Teorema 2}

Misalkan fungsi permintaan adalah fungsi kontinu, dengan menggunakan 
asumsi batasan interval diperoleh $\boldsymbol{Q}(\boldsymbol{\pi})=\widetilde{\boldsymbol{P}}(\boldsymbol{D}(\boldsymbol{\pi}))=\widetilde{\boldsymbol{P}}\left(\left(D_{1}(\pi), \cdots, D_{k}(\pi)\right)\right)$, maka pada titik kesetimbangan terdapat vektor premi $\pi^{*}=\left(\pi_{1}^{*}, \cdots, \pi_{k}^{*}\right)$ yang memenuhi:

$$
\boldsymbol{Q}\left(\boldsymbol{\pi}^{*}\right)=\boldsymbol{Q}\left(\pi_{1}^{*}, \cdots, \pi_{k}^{*}\right)=\boldsymbol{\pi}^{*}
$$

\section{b. Karakteristik dari Titik Kesetimbangan}

Fungsi harga pada persaman (8) pada titik kesetimbangan berdasarkan teorema titik tetap menjadi persamaan (5), sedangkan fungsi permintaan pada titik kesetimbangan menggunakan teorema berikut.

\section{Teorema 3}

Suatu vektor $\pi^{*}=\left(\pi_{1}^{*}, \cdots, \pi_{k}^{*}\right)$ adalah titik tetap dari $Q(\pi)$ jika dan hanya jika, untuk $j=1, \cdots, k$ memenuhi:

$$
D_{j}\left(\pi^{*}\right)=\frac{r_{j}}{\left(\pi_{j}^{*}-\mu_{j}\right)} a
$$

\section{Bukti:}

Syarat perlu: asumsikan bahwa $\pi^{*}$ titik kesetimbangan, sehingga persamaan (8) menjadi:

$$
\boldsymbol{\pi}^{*}=\mu_{j}+\frac{r_{j}}{D_{j}\left(\boldsymbol{\pi}^{*}\right)} a,
$$

Syarat cukup: substitusikan $D_{j}\left(\boldsymbol{\pi}^{*}\right)$ dalam persamaan (12) ke dalam persamaan (13) didapatkan

$$
\mu_{j}+\frac{r_{j}}{D_{j}\left(\pi^{*}\right)} a=\mu_{j}+\frac{\alpha r_{j}}{a r_{j} /\left(\pi_{j}^{*}-\mu_{j}\right)}=\pi^{*}
$$

Jadi berdasarkan asumsi diatas, $\boldsymbol{\pi}^{*}$ adalah titik kesetimbangan.

Berdasarkan asumsi batasan interval, maka fungsi permintaan $\left(D_{j}\left(\pi_{j}\right)\right)$ dan batasan intervalnya sebagai berikut:

$$
D_{j}\left(\pi_{j}\right)=\left\{\begin{array}{lc}
\frac{f_{j}}{\pi_{j}-\mu_{j}} & \mu_{j}<m_{j} \leq \pi_{j} \leq M_{j} \\
\frac{f_{j}}{M_{j}-\mu_{j}} & \pi_{j} \geq M_{j} \\
\frac{f_{j}}{m_{j}-\mu_{j}} & \pi_{j} \leq m_{j}
\end{array}\right.
$$

dimana $f_{j}=a r_{j}, M_{j}, m_{j}$ adalah batas atas dan bawah interval dari besarnya premi $\left(\pi_{j}\right)$.

Pada titik kesetimbangan untuk kelas ke- $j, j=1, \cdots, k$, rataan dan 
ragamnya adalah berturut-turut $\mu_{j}$ dan $\sigma_{j}^{2}$, sedangkan ragam total pada titik kesetimbangan adalah:

$$
\sigma^{2}=\sum_{j=1}^{k} D_{j}\left(\pi^{*}\right) \sigma_{j}^{2}
$$

\section{Perhitungan Titik Kesetimbangan dengan Pendekatan Pertama}

Perhitungan besarnya premi menggunakan pendekatan pertama yaitu persamaan (4) dan persamaan (15) maka parameter $a$ adalah:

$$
a=\frac{q_{1-\alpha} \sqrt{\sum_{j=1}^{k} D_{j}\left(\pi^{*}\right) \sigma_{j}^{2}}}{r}
$$

dan nilai $f_{j}=q_{1-\alpha} d_{j} r_{j}$, untuk $j=1, \cdots, k$. Harga premi pada titik kesetimbangan adalah:

$$
\pi_{j}^{*}=\mu_{j}+q_{1-\alpha} d_{j} \sigma_{j}^{2}, \text { untuk setiap } M_{j}, j=1, \cdots, k
$$

dalam interval $m_{j} \leq \mu_{j}+q_{1-\alpha} d_{j} \sigma_{j}^{2} \leq M_{j}, \quad j=1, \cdots, k$

Karena $d_{j}=1 / \sqrt{r}$, maka persamaan (17) menjadi:

$$
\pi_{j}^{*}=\mu_{j}+q_{1-\alpha} \frac{\sigma_{j}^{2}}{\sqrt{r}}, \quad j=1, \cdots, k
$$

dengan menyubstitusikan persamaan (17) ke dalam persamaan (14) dihasilkan persamaan sebagai berikut:

$$
D_{j}\left(\pi^{*}\right)=\frac{r_{j}}{\sigma_{j}^{2}}
$$

\section{Perhitungan Titik Kesetimbangan dengan Pendekatan Kedua}

Perhitungan harga premi berdasarkan pendekatan kedua, yaitu persamaan (7) dengan parameter $a$ didapatkan dengan persamaan

$$
a=\sqrt{\frac{t}{r} \sum_{j=1}^{k} \frac{D_{j}\left(\pi^{*}\right) \sigma_{j}^{2}}{r_{j}}},
$$

dimana $t>0$ serta nilai $f_{j}=t d_{j} r_{j}, j=1, \cdots, k$, dengan konstanta $d_{j}, j=$ $1, \cdots, k$, sehingga didapat besar premi pada titik kesetimbangan yaitu:

$$
\pi_{j}^{*}=\mu_{j}+t d_{j} \sigma_{j}^{2} \text { untuk setiap } j=1, \cdots, k
$$


dalam interval $m_{j} \leq \mu_{j}+t d_{j} \sigma_{j}^{2} \leq M_{j}$.

Selanjutnya dengan menyubstitusi persamaan (21) ke dalam persamaan (14) didapat:

$$
D_{j}\left(\pi^{*}\right)=\frac{r_{j}}{\sigma_{j}^{2}}
$$

Kemudian persamaan (21) dan (22) disubtitusikan ke dalam persamaan (7) didapatkan:

$$
\pi_{j}^{*}=\mu_{j}+\frac{r_{j} \sigma_{j}^{2}}{\sqrt{r} r_{j}} \sqrt{\sum_{j=1}^{k} \frac{t \sigma_{j}^{2}}{r_{j}} \frac{r_{j}}{\sigma_{j}^{2}}}=\mu_{i}+\sqrt{\frac{k t}{r}} \sigma_{j}^{2} .
$$

Oleh karena $d_{1}=d_{2}=\cdots=d_{k}=\sqrt{k} / \sqrt{r t}$, maka harga premi pada saat kesetimbangan adalah:

$$
\pi_{j}^{*}=\mu_{j}+t d_{j} \sigma_{j}^{2}=\mu_{j}+\frac{\sqrt{k t}}{\sqrt{r}}, \text { untuk setiap } j=1, \cdots, k
$$

\section{Contoh Kasus Perhitungan}

Misalkan suatu perusahaan asuransi menawarkan produk asuransi yang berjangka waktu satu tahun kepada nasabah, dengan karakteristiknya tertuang dalam suatu portofolio yang terdiri atas lima kelas risiko, peluang terjadinya klaim untuk tiap kelas risiko adalah $q_{j}$, dengan rataan $\omega_{j}$ dan ragamnya $v_{j}^{2}$. Sedangkan rataan untuk tiap kelas adalah $\mu_{j}$ dan ragamnya $\sigma_{j}^{2}$. Seperti yang diperlihatkan dalam tabel (1), dengan asumsi mengikuti sebaran normal baku dan $n_{j}$ berjumlah cukup besar sehingga berlaku teorema limit pusat.

Tabel 1. Perhitungan Rataan dan Ragam dari Lima Kelas Risiko

\begin{tabular}{cccccc}
\hline $\begin{array}{c}\text { Kelas } \\
\boldsymbol{j}\end{array}$ & $\begin{array}{c}\text { Peluang } \\
\text { terjadinya } \\
\text { klaim }\end{array}$ & $\boldsymbol{\omega}_{\boldsymbol{j}}$ & $\boldsymbol{v}_{\boldsymbol{j}}^{\mathbf{2}}$ & $\begin{array}{c}\text { Rataan } \\
\boldsymbol{\mu}_{\boldsymbol{j}}=\boldsymbol{q}_{\boldsymbol{j}} \boldsymbol{\omega}_{\boldsymbol{j}}\end{array}$ & $\begin{array}{c}\text { Ragam } \\
\boldsymbol{\sigma}_{\boldsymbol{j}}^{2}=\boldsymbol{\mu}_{\boldsymbol{j}}^{\mathbf{2}} \boldsymbol{q}_{\boldsymbol{j}}\left(\mathbf{1}-\boldsymbol{q}_{\boldsymbol{j}}\right) \\
+\boldsymbol{v}_{\boldsymbol{j}}^{\mathbf{2}} \boldsymbol{q}_{\boldsymbol{j}}\end{array}$ \\
\hline 1 & & & & & 214,475 \\
2 & 0.050 & 2,100 & 100,000 & 105 & $9,020,000$ \\
3 & 0.100 & 10,000 & 200,000 & 1,000 & $28,058,100$ \\
4 & 0.210 & 13,000 & 100,000 & 2,730 & $35,034,375$ \\
5 & 0.185 & 15,000 & $6,000,000$ & 2,775 & $56,187,500$ \\
\hline
\end{tabular}

Perhitungan secara numerik diperoleh untuk masing-masing kelas pada titik kesetimbangan harga premi $\pi_{j}^{*}$, dan jumlah tertanggung $n_{j}=D\left(\pi^{*}\right)$ dengan bantuan perangkat lunak Mathematica, diperlihatkan hasil perhitungannya pada tabel (1) dan tabel (2).

Pada tabel (2) perhitungan nilai $f_{j}$ dan $r_{j}$ tiap kelas risiko dilakukan dengan menggunakan pendekatan pertama, serta ditetapkan nilai $\alpha=0.20$ 
sehingga didapatkan nilai $q_{1-\alpha}=0.8416$, pada titik kesetimbangan harga premi $\pi_{j}^{*}$, dan jumlah tertanggung $n_{j}=D\left(\pi^{*}\right)$, masing-masing dihitung dengan menggunakan persamaan (18) dan (19).

Tabel 2. Perhitungan pada titik kesetimbangan dengan menggunakan pendekatan pertama

\begin{tabular}{ccccc}
\hline Kelas & $\boldsymbol{f}_{\boldsymbol{j}}$ & $\boldsymbol{r}_{\boldsymbol{j}}$ & $\boldsymbol{\pi}_{\boldsymbol{j}}^{*}$ & $\boldsymbol{n}_{\boldsymbol{j}}=\boldsymbol{D}\left(\boldsymbol{\pi}^{*}\right)$ \\
\hline 1 & 51,000 & $4.3 \mathrm{E}+09$ & 107.57 & $19,835.44$ \\
2 & 48,000 & $4.0 \mathrm{E}+09$ & $1,108.13$ & 443.90 \\
3 & 38,000 & $3.2 \mathrm{E}+09$ & $3,066.36$ & 112.97 \\
4 & 35,000 & $2.9 \mathrm{E}+09$ & $3,193.23$ & 83,69 \\
5 & 31,000 & $2.6 \mathrm{E}+09$ & $4,920.74$ & 46,22 \\
\hline
\end{tabular}

Dari proses perhitungan, dimana jumlah tertanggung $\left(n_{j}\right)$ merupakan bilangan bulat yang dinyatakan dalam suatu vektor sebagai berikut:

$$
\begin{array}{ll}
\tilde{n}^{1}=(19835,443,112,83,47) & \tilde{n}^{5}=(19836,443,112,83,46) \\
\tilde{n}^{2}=(19835,443,113,83,47) & \tilde{n}^{6}=(19836,443,113,84,46) \\
\tilde{n}^{3}=(19835,444,112,84,46) & \tilde{n}^{7}=(19836,444,112,84,47) \\
\tilde{n}^{4}=(19835,444,113,84,46) & \tilde{n}^{8}=(19836,444,113,84,47)
\end{array}
$$

Perbedaan perhitungan vektor jumlah tertanggung dari $\tilde{n}^{1}, \cdots, \tilde{n}^{8}$ terlihat relatif kecil. Pada titik kesetimbangan, 19836 jumlah tertanggung membayar premi sebesar 107.57, 444 jumlah tertanggung membayar premi sebesar 1,108.13, 113 jumlah tertanggung membayar premi sebesar 3,066.36, 84 jumlah tertanggung membayar premi sebesar 3,193.23 dan 47 jumlah tertanggung membayar premi sebesar 4,920.74.

Perhitungan dengan menggunakan pendekatan kedua, dengan data yang sama seperti contoh sebelumnya, dan diberikan nilai $t=0.15$ dengan nilai $f_{j}$ yang sama dengan tabel (2) serta menggunakan persamaan (21) dan (22), harga premi dan jumlah tertanggung pada titik kesetimbangan diperoleh sebagai berikut:

Tabel 3 Perhitungan pada titik kesetimbangan dengan menggunakan pendekatan kedua

\begin{tabular}{ccccc}
\hline Kelas & $\boldsymbol{f}_{\boldsymbol{j}}$ & $\boldsymbol{r}_{\boldsymbol{j}}$ & $\boldsymbol{\pi}_{\boldsymbol{j}}$ & $\boldsymbol{n}_{\boldsymbol{j}}=\boldsymbol{D}\left(\boldsymbol{\pi}^{*}\right)$ \\
\hline 1 & 51,000 & $1.55 \mathrm{E}+10$ & 105.70 & $72,393.83$ \\
2 & 48,000 & $1.46 \mathrm{E}+10$ & $1,029.63$ & $1,620.10$ \\
3 & 38,000 & $1.16 \mathrm{E}+10$ & $2,822.16$ & 412.32 \\
4 & 35,000 & $1.07 \mathrm{E}+10$ & $2,890.08$ & 304.15 \\
5 & 31,000 & $9.44 \mathrm{E}+09$ & $4,434.56$ & 167.97 \\
\hline
\end{tabular}

Proses perhitungan vektor jumlah tertanggung untuk kasus yang kedua adalah sebagai berikut: 


$$
\begin{array}{ll}
\tilde{n}^{1}=(72393,1620,412,304,167) & \tilde{n}^{5}=(72394,1620,412,304,168) \\
\tilde{n}^{2}=(72393,1620,413,304,167) & \tilde{n}^{6}=(72393,1621,413,304,168) \\
\tilde{n}^{3}=(72393,1621,412,304,168) & \tilde{n}^{7}=(72394,1621,412,305,168) \\
\tilde{n}^{4}=(72393,1621,413,304,168) & \tilde{n}^{8}=(72394,1621,413,305,168)
\end{array}
$$

Perbedaan perhitungan vektor jumlah tertanggung dari $\tilde{n}^{1}, \cdots, \tilde{n}^{8}$ terlihat relatif kecil. Pada titik kesetimbangan 72394 jumlah tertanggung membayar premi sebesar 105.70, 1621 jumlah tertanggung membayar premi sebesar 1,029.63, 413 jumlah tertanggung membayar premi sebesar 2,822.16, 305 jumlah tertanggung membayar premi sebesar 2,890.08 dan 168 jumlah tertanggung membayar premi sebesar 4,434.56.

\section{SIMPULAN DAN SARAN}

Hasil dari simulasi perhitungan dengan menggunakan pendekatan pertama dan pendekatan kedua adalah diperoleh harga premi dengan jumlah tertanggung masing-masing kelas risiko relatif tidak sama untuk dua pendekatan tersebut.

Perbedaan pada titik kesetimbangan antara pendekatan pertama dan kedua disebabkan perbedaan besarnya ragam ditiap kelas risiko yang menyebabkan perbedaan pada harga premi melalui persamaan (11) dan (17). Perbedaan besarnya ragam ditiap kelas risiko juga berpengaruh terhadap perbedaan jumlah tertanggung melalui persamaan (12) dan (15), sebagai catatan ragam untuk kelas ke-tiga sekitar tiga kali dari ragam kelas ke-dua dan 130 kali dari ragam kelas kesatu.

Disarankan untuk diadakan penelitian lebih lanjut yaitu penentuan harga premi dan banyaknya jumlah tertanggung di tiap kelas risiko menggunakan asumsi masing-masing kelas merupakan portofolio homogen dan dibandingkan dengan hasil penelitian ini.

DAFTAR RUJUKAN

Bowers NL, Gerber HU, Hickman JC, Jones DA, dan Nesbitt CJ. (1997). Actuarial Mathematics. The Society of Actuaries. New York.

Frostig E, Zaks Y, dan Levikson B. (2008) . Pricing a Heterogeneous Portofolio Based on A Demand Function. NAAJ 12(1):65-73.

Golberg RR.(1976). Method of Real Analysis. John Willey \& Sons. New York.

Grimmett GR, Strizaker DR. (2001). Probability and Random Processes. Ed. ke3. Oxford: Clarendon Press.

Ross SM. (1996). Stochastic Processes. John Willey \& Sons. New York.

Zaks Y, Frostig E, dan Levikson B. (2006) . Optimal Pricing of a Heterogeneous Portofolio for a Given Risk Level. ASTIN Bulletin 36(1):161-85. 